\title{
Respiratory functions of conservancy workers working in solid waste management sector of Chennai, India
} [v1; ref status: approved 1, approved with reservations 1,
http://f1000r.es/TyPM5P]

Srinivasan Roopa ${ }^{1}$, Ramaswamy Padmavathi ${ }^{1}$, Avinash Akolkar ${ }^{2}$, Sambandam Sankar ${ }^{3}$, Pitani Ravishankar ${ }^{4}$, Thanasekharaan Vijayalakshmi ${ }^{5}$, Subhashini A.S. ${ }^{1}$, Balakrishnan Kalpana ${ }^{3}$

\footnotetext{
${ }^{1}$ Department of Physiology, Sri Ramachandra Medical College \& Research Institute, Sri Ramachandra University, Porur, Chennai - 600 116, Tamil Nadu, India

${ }^{2}$ Central Pollution Control Board, New Delhi -110 032, India

${ }^{3}$ Department of Environmental Health Engineering, Sri Ramachandra Medical College \& Research Institute, Sri Ramachandra University, Chennai - 600 116, Tamil Nadu, India

${ }^{4}$ Department of Community Medicine, Sri Ramachandra Medical College \& Research Institute, Sri Ramachandra University, Chennai - 600116 , Tamil Nadu, India

${ }^{5}$ Department of Chest Medicine, Sri Ramachandra Medical College \& Research Institute, Sri Ramachandra University, Chennai - 600 116, Tamil Nadu, India
}

Correspondence to Srinivasan Roopa: roopa2208@gmail.com

V1 First published: 13 December 2012, 1:67 (doi: 10.3410/f1000research.1-67.v1)

(C) Usage Licensed by Creative Commons CC-BY 3.0

\begin{abstract}
How to cite this article: Roopa S, Padmavathi R, Akolkar A et al. (2012) Respiratory functions of conservancy workers working in solid waste management sector of Chennai, India [v1; ref status: approved 1, approved with reservations 1, http://f1000r.es/TyPM5P] F1000Research 1:67 (doi: 10.3410/f1000research.1-67.v1)
\end{abstract}

\begin{abstract}
Chennai is the fourth largest metropolitan city in India. Around 10,000 conservancy workers of the Chennai Corporation handle about $\mathbf{4 5 0 0}$ to 5200 tons of solid wastes per day. These workers are exposed to a lot of environmental and occupational hazards affecting the respiratory system. This paper presents the results of pulmonary function assessment in 178 conservancy workers (100 sweepers \& 78 loaders) of the Chennai Corporation. Detailed medical and occupational history was obtained and clinical examination was performed after obtaining informed consent. Pulmonary functions (forced vital capacity [FVC], forced expiratory volume in 1 second [FEV1] and peak expiratory flow rate [PEFR]) were measured using a portable spirometer.

Since normal pulmonary function values for healthy non-smoking South Indian adults are available through previously published studies, the pulmonary function test (PFT) values from the study group were compared with the predicted values after corrections for age and anthropometry. The pulmonary functions of the conservancy workers were significantly lower than their predicted values. Moreover, the pulmonary functions declined with increasing years of working. Among both the groups of conservancy workers, the pulmonary functions were significantly lower in sweepers than loaders $(P<0.01)$. This study has generated lung function data of the Chennai Corporation conservancy workers that can aid the concerned authorities to implement specific interventions to reduce the exposure and improve the health status of the workers.
\end{abstract}

\section{Introduction}

The Chennai metropolitan area is the fourth largest metropolis in India. Urban development has been rapid over the last two decades. The development process, however, has had an adverse impact on the environment in the metropolis ${ }^{1}$. Municipal solid waste management (MSWM) is one of the major environmental problems of Indian cities. Increasing volumes, entry of select hazardous waste streams, manual handling of wastes, inadequate personal protective equipment, lack of awareness about health and sanitation and inadequate environmental management at the landfill sites expose conservancy workers to a multitude of environmental and occupational hazards. 
Chennai city is divided into 10 zones $^{2}$. More than 10,000 conservancy workers of the Chennai Corporation handle 4500 to 5200 tons of municipal solid wastes per day. Per-capita generation of solid waste is $0.7 \mathrm{~kg}$ per day ${ }^{3}$. The waste disposal sites of Chennai are the Kodungaiyur and the Perungudi dumping grounds. Although the incidence and prevalence of various hazards in formal solid waste sector workers are high, very few studies have been conducted in developing countries ${ }^{4}$. Studies have been published from the developed high-income countries $^{5}$. The data from these developed countries cannot be directly extrapolated to developing countries, as the entire scenario is different between the two. The health profile in the Solid Waste Management sector needs to be generated region wise in order to implement the appropriate preventive and corrective measures. This study was not designed to establish the causative role of particular workplace exposures for the observed health impairments, but rather to evaluate the pulmonary function of workers in this environment with the intention of aiding subsequent environmental health management initiatives aimed at preventing such job-related exposures.

\section{Methods}

The present cross sectional study was carried out among 178 conservancy workers of the Chennai Corporation. This project was executed in collaboration with the Chennai Metropolitan Development Authority and the Corporation of Chennai. Permissions were obtained from the Commissioner of Chennai Municipal Corporation, Superintending Engineer of Solid Waste Management and the Chennai Corporation Health Officer. The Solid Waste Management sector in the Corporation of Chennai is directly under supervision of the Superintending Engineer.

The 10,896 conservancy workers of the Chennai Corporation are spread all over the city across 10 zones and 155 wards. 178 conservancy workers were recruited for this study. Using Probability Proportionate to Sample (PPS), six zones (zones 2, 3, 4, 5,7 and 9) were identified for the study purpose. Workers were then selected randomly from the roster.

The study proposal was approved by the corresponding author's Institutional Ethics Committee. Written informed consent was obtained from all the subjects involved in the study for publications of their clinical details, prior to administration of medical examination. A validated questionnaire was used for obtaining medical history and occupational history of patients. A detailed clinical examination was performed on all the subjects, which included a general examination and respiratory system examination.

Pulmonary function tests (PFT) were performed using portable data-logging Spirometer (MIR SPIROBANK - Model A23). This spirometer works on the infrared interruption principle, where an infrared miniflow sensor is used for measurement of both flow and volume. All the workers were properly trained to perform the pulmonary function test. All the subjects underwent an anthropometric assessment, which included height and weight. A nose clip was fixed and the test was performed in a sitting position. The best value of three attempts was taken. A complete flow - volume loop was obtained from the spirometer. The spirograms (flow - volume loop) were directly downloaded from the instrument and printed, and the values were also manually recorded. The Spirometer that was used performs as per the equipment specifications of the American Thoracic Society. All volumes were corrected to conditions of body temperature and pressure saturable with water vapour (BTPS). The best values of Forced Vital Capacity (FVC), Forced Expiratory Volume at the end of one second (FEV1) and Peak Expiratory Flow Rate (PEFR) were used for analysis.

Data are represented as Mean \pm Standard Deviation. The comparison test of significance used was the independent ' $t$ ' test. Pearson's correlation analysis and linear regression were used for assessing the association of pulmonary function parameters with total duration of employment. The level of significance was taken at the 5\% level. Data were analysed using SPSS version 16 .

\section{Results}

The age, height, weight and BMI (Body mass index) of the 178 conservancy workers (study subjects) are provided in Table I.

Table I Anthropometric parameters of the study subjects.

\begin{tabular}{|lll|}
$\begin{array}{l}\text { Anthropometric } \\
\text { measurements }\end{array}$ & Sweepers $(\mathbf{n}=\mathbf{1 0 0})$ & Loaders $(\mathbf{n}=\mathbf{7 8})$ \\
\hline Age $(\mathrm{yrs})$ & $44.64 \pm 8.61$ & $44.01 \pm 6.61$ \\
\hline Height $(\mathrm{cm})$ & $154.42 \pm 9.74$ & $161.79 \pm 6.57$ \\
\hline Weight $(\mathrm{Kg})$ & $54.99 \pm 11.28$ & $55.92 \pm 9.79$ \\
\hline $\mathrm{BMl}\left(\mathrm{Kg} / \mathrm{m}^{2}\right)$ & $23.1 \pm 4.52$ & $21.39 \pm 3.83$ \\
\hline
\end{tabular}

All values are represented as Mean \pm Standard deviation; $\mathrm{BMI}=$ Body mass index.

Results of Pulmonary function assessment: The key pulmonary function parameters chosen for analysis were FVC, FEV1 and PEFR. Females had lower pulmonary function than males. The pulmonary function parameters of the study subjects are provided in Table II.

Since normal pulmonary function values for healthy nonsmoking South Indian adults are available through previously published studies ${ }^{6,7}$, the PFT values of non smoking men and women from the study group were compared with the predicted values after corrections for age and anthropometry. The study population, both males and females had lower observed values than their own predicted values, which were statistically significant. 
Table II Pulmonary function parameters of the study subjects.

${ }^{*} \mathrm{P}<0.01$; Sweepers had significantly lower values compared to loaders.

\begin{tabular}{lll}
$\begin{array}{l}\text { Pulmonary function } \\
\text { parameters }\end{array}$ & $\begin{array}{l}\text { Sweepers* } \\
(\mathbf{n}=\mathbf{1 0 0})\end{array}$ & Loaders $(\mathbf{n}=\mathbf{7 8})$ \\
\hline FVC & $2.22 \pm 0.77$ & $2.88 \pm 0.68$ \\
\hline FEV1 & $1.86 \pm 0.62$ & $2.39 \pm 0.59$ \\
\hline PEFR & $5.17 \pm 1.89$ & $6.45 \pm 1.83$ \\
\hline
\end{tabular}

All values are represented as Mean \pm Standard deviation.

FVC = Forced Vital Capacity; FEV1 = Forced Expiratory volume at the end of one second; PEFR = Peak expiratory flow rate.

In order to discern differences among both the categories of workers, who have varying degrees of occupational exposures, PFT values of both the job categories were compared. Sweepers had the lower PFT (FVC, FEV1 and PEFR) values compared to loaders, which were statistically significant, as shown in Table II.

PFT values were also compared across both the groups of workers with varying duration of work experience (resulting in differences in duration of exposure) as shown in Figure 1. The workers were classified into three groups based on the duration of working (Group I: work duration <10yrs; Group II: work duration 10-20yrs; Group III: work duration >20yrs). Pulmonary functions were significantly lower in the group III, compared to group I and group II. FVC and FEV1 were significantly different among the three groups. PEF of Group I was significantly different when compared with Group II and Group III, whereas there was no difference between Group II and Group III. Pulmonary function significantly declined with increasing years of working as assessed by linear regression.

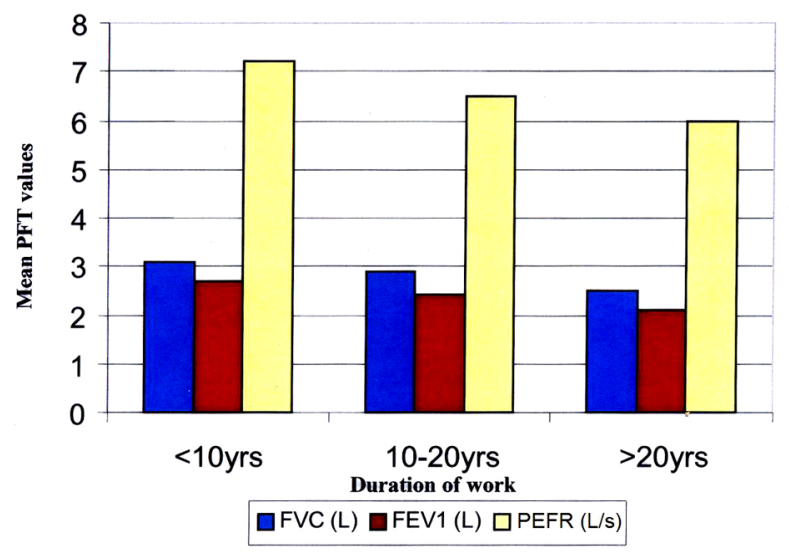

Figure 1 Pulmonary functions in both the groups of conservancy workers based on duration of working. (Group I: <10yrs; Group II: 10-20yrs; Group III: >20yrs) FVC = Forced Vital Capacity; FEV1 $=$ Forced Expiratory volume at the end of one second; PEFR $=$ Peak expiratory flow rate.

\section{Discussion}

This study has generated the pulmonary function profile of the conservancy workers of the Solid Waste Management sector of Chennai. There is higher prevalence of both respiratory symptoms and respiratory impairments (as established through pulmonary function tests) in the study population. The decrement in pulmonary function with increasing duration of working strongly suggests that workplace exposures may be contributing significantly to such impairments. A very high prevalence of respiratory symptoms, much lower lung function values than predicted for a normal healthy population, increasing impairments with increasing years of working all point to a pattern of increased potential for respiratory morbidity among these workers due to occupational exposures. Exposures to air pollutants including dusts, air toxins and bio-aerosols from fugitive and occupational sources are a major health concern for conservancy workers. It is likely that operations such as sweeping, loading and unloading solid wastes could potentially expose workers to greater than safe levels, as all such operations were being performed in the absence of any engineering controls or use of personal protective equipment (PPE). In the present study, the conservancy workers did not use any PPE.

Studies have reported higher respiratory morbidity among conservancy workers. In a study conducted by Athanasiou et al., municipal solid waste workers had increased symptoms pertaining to respiratory system and a significant reduction in FVC compared with controls ${ }^{8}$. Ray et al. also reported that landfill workers had a significantly higher prevalence of respiratory symptoms and increased impairment of lung function compared with controls. The landfill workers also had airway inflammation and a lot of complaints pertaining to general health' ${ }^{9}$. Rajnarayan R. Tiwari reported that the abnormal respiratory functions found in sanitary workers may be due to exposure to endotoxins and airborne bacteria by way of bioaerosols ${ }^{10}$. Zuskin et al. reported that forced end expiratory flow FEF50 and FEF25 were reduced, probably due to small airway obstruction $^{11}$. In another study, Zuskin et al. have demonstrated reduced FVC and FEV1, which was significant in sanitation workers compared with controls ${ }^{12}$. Similar significant reductions in lung function parameters have been reported in solid waste collectors in other studies ${ }^{13}$.

The present study demonstrates the degree of pulmonary impairments prevalent in workers of this sector. Given the similarity in process operations across other districts in the state, as well as other states in South India, this may be a fair representation of the sector in South India.

Baseline health assessments in these work environments further provide the necessary inputs for designing surveillance programs. Pulmonary functions assessment is also a pre-requisite for assessing fitness to wear respirators and hence must be periodically 
conducted. It is important to implement control strategies at an early stage to prevent the disease process from setting in and also it would be crucial for these workers to be covered under a regular occupational health-monitoring program that would keep them under routine surveillance. Sector-specific exposure and health profiling is an important element for creation of local occupational health databases and the results of the study have provided baseline information to serve as an input to the development of such databases.

Longitudinal studies can be planned with the input available from this study to assess the chronic or permanent functional loss resulting from exposure. Further work is also needed to clarify potential reversibility after cessation of exposure. Medical institutions and the Occupational Health Institute need to be encouraged to study the health of conservancy workers with an appropriate baseline control population, since epidemiological data from this sector is lacking. Apart from all these, an environmentally sound garbage management system is required for urban waste management ${ }^{14}$. A proper method should be used to dispose of solid waste ${ }^{15}$.

\section{Conclusion}

This profile can be used to address the hazards identified in solid waste management, so that appropriate preventive and corrective measures can be undertaken. The issue of occupational health in India is deeply embedded in a matrix of environmental, health, and economic/developmental considerations. Understanding the potential for health risks is necessary to ensure that the most vulnerable communities need not suffer. Indeed if human development is the goal, addressing health risks is an important mechanism to ensure equity in quality of life for all and it is hoped that the information presented here represents a small incremental step towards achieving the same.

\section{Author contributions}

Roopa S, R. Padmavathi, B. Kalpana and A. Akolkar conceived and designed this paper. Roopa $S$ and S. Sankar acquired the data and drafted the article. R. Padmavathi revised it for intellectual content. P. Ravishankar analysed and interpreted the data. T. Vijayalakshmi and Subhashini A.S. helped in final approval of the version to be published.

\section{Grant information}

The present study was funded by the Central Pollution Control Board, New Delhi, India.

\section{Competing interests}

There are no competing interests.

\section{Consent}

Written informed consent for publications of their clinical details was obtained from all the subjects involved in the study.
1. Sujatha $P$, Janardhanam PVS. Solid waste management in Chennai city. Indian J Edu Inf Manage, Mar 2012; 1(3), pp. 115-125.

2. Sudhir V, Muraleedharan VR, Srinivasan G. Integrated solid waste management in urban India: A critical operational research framework. Socio-Econ. Plann. Sci, 1996; 30(3), pp. 163-181.

3. http://www.chennaicorporation.gov.in/departments/solid-wastemanagement/index.htm

4. Misra V, Pandey SD. Hazardous waste, impact on health and environment for development of better waste management strategies in future in India. Environ Int, Apr 2005; 31(3), pp. 417-31.

5. Lennart Friis, Dan Norback, Christer Edling. Self-Reported Asthma and Respiratory Symptoms in Sewage Workers. J Occup Health 1999; 41, pp. 87-90.

6. Vijayan VK, Kuppurao KV, Venkatesan P, Sankaran K. Reference values and prediction equations for maximal expiratory low rates in non-smoking normal subjects in Madras. Indian J Physiol Pharmacol, 1993; 37(4), pp. 291-297.

7. Vijayan VK, Kuppurao KV, Venkatesan P, Sankaran K, Prabhakar R. Pulmonary functions in healthy young adult Indians in Madras. Thorax 1990; 45 pp. 611-615.

8. Athanasiou M, Makrynos G, Dounias G. Respiratory health of municipal solid waste workers. Occup Med (Lond), Sep 2010; 60, pp. 618-623.

9. Ray MR, Roychoudhury S, Mukherjee G, Roy S, Lahiri T. Respiratory and general health impairments of workers employed in a municipal solid waste disposal at an open landfill site in Delhi. Int J Hyg Environ Health, 2005; 208(4), pp. 255-62.

10. Rajnarayan R. Tiwari. Occupational health hazards in sewage and sanitary workers. Indian Journal of Occupational and Environmental Medicine, Dec 2008; 12(3), pp. 112-115.

11. Zuskin E, Mustajbegovic J, Schachter EN. Resiratory function in sewage workers. Am J Ind Med, 1993; 23, pp. 751-61.

12. Zuskin E, Mustajbegovic J, Schachter EN, Kern J, Pavicic D, Budak A. Airway function and respiratory symptoms in sanitation workers. J Occup Environ Med, May 1996; 38(5), pp. 522-7.

13. Heldal KK, Halstensen AS, Thorn J, Eduard W, Halstensen TS. Airway inflammation in waste handlers exposed to bioaerosols assessed by induced sputum. Eur Respir J, 2003; 21, pp. 641-645.

14. Dhande AD, Ingle ST, Attarde SB, Wagh ND. Ecofriendly approach of urban solid waste management: a case study of Jalgaon city, Maharashtra. J Environ Biol, Oct 2005; 26(4), pp. 747-52.

15. Avinash Puri, Manoj Kumar, Eonkar Johal. Solid-waste management in Jalandhar city and its impact on community health. Indian J Occup Environ Med, Aug 2008; 12(2), pp. 76-81. 


\section{Open Peer Review}

\section{Current Peer Review Status:}

\section{Version 1}

Reviewer Report 24 January 2013

https://doi.org/10.5256/f1000research.250.r727

(C) 2013 Nemery de Bellevaux B. This is an open access peer review report distributed under the terms of the Creative Commons Attribution License, which permits unrestricted use, distribution, and reproduction in any medium, provided the original work is properly cited.

\section{Benoit Nemery de Bellevaux}

Occupational, Environmental and Insurance Medicine, Department of Public Health , University of Leuven, Leuven, Belgium

The methodology of the field survey appears to have been adequate. However, the analysis is not adequate.

The authors should not base their analysis on absolute levels of pulmonary function parameters. Indeed the differences observed between sweepers and loaders (table 2) and between age groups (figure 1) could simply be due to differences in sex (how many men and women were there in each group?), height (table 1 shows a $7 \mathrm{~cm}$ difference in mean height between sweepers and loaders!) or even age distribution. In other words, the authors should have analyzed their data taking into account these 3 factors, either by doing a multiple correlation analysis or by taking values in percent predicted (which they probably did, but they don't present the data).

Competing Interests: No competing interests were disclosed.

I confirm that I have read this submission and believe that I have an appropriate level of expertise to confirm that it is of an acceptable scientific standard, however I have significant reservations, as outlined above.

Author Response 05 Jun 2013

Srinivasan Roopa, Sri Ramachandra Medical College \& Research Institute, Sri Ramachandra University, Porur, Chennai, India

As Dr Nemery de Bellavaux has mentioned, analyses of data was actually done by comparing pulmonary function values of the study subjects with their predicted values. Normal pulmonary function values for healthy non-smoking South Indian adults are available through previously published studies (References 6,7 and the equations of Vijayan et al). The data was not presented earlier, but now the data is presented as Table II. The PFT of the study group were compared with the predicted values (for men and women 
respectively) after corrections for age and anthropometry. The study population, both males and females had lower observed values than their own predicted values, which were statistically significant as shown in the Table II. Table II: Observed and predicted pulmonary function values of the study population Parameter Observed values Predicted values Males FVC $2.8 \pm 0.73 .2 \pm 0.5 * \mathrm{FEV}_{1} 2.4 \pm 0.53 .0 \pm 0.4$ * Females FVC $1.9 \pm 0.52 .3 \pm 0.2 * \mathrm{FEV}_{1} 1.6 \pm$ $0.51 .9 \pm 0.2 *$ Data expressed as Mean $\pm S D * P<0.05$. Figure 1 shows the Pulmonary functions in both the groups of conservancy workers (i.e. sweepers and loaders) based on duration of working and not age groups. The authors thank the referees for their responses and their comments are well taken.

Competing Interests: There are no competing interests.

Reviewer Report 19 December 2012

https://doi.org/10.5256/f1000research.250.r403

(C) 2012 Liu Y. This is an open access peer review report distributed under the terms of the Creative Commons Attribution License, which permits unrestricted use, distribution, and reproduction in any medium, provided the original work is properly cited.

\section{Youcheng Liu}

Department of Environmental and Occupational Health, University of North Texas Health Science Center, Fort Worth, TX, USA

Competing Interests: No competing interests were disclosed.

I confirm that I have read this submission and believe that I have an appropriate level of expertise to confirm that it is of an acceptable scientific standard. 
The benefits of publishing with F1000Research:

- Your article is published within days, with no editorial bias

- You can publish traditional articles, null/negative results, case reports, data notes and more

- The peer review process is transparent and collaborative

- Your article is indexed in PubMed after passing peer review

- Dedicated customer support at every stage

For pre-submission enquiries, contact research@f1000.com 